
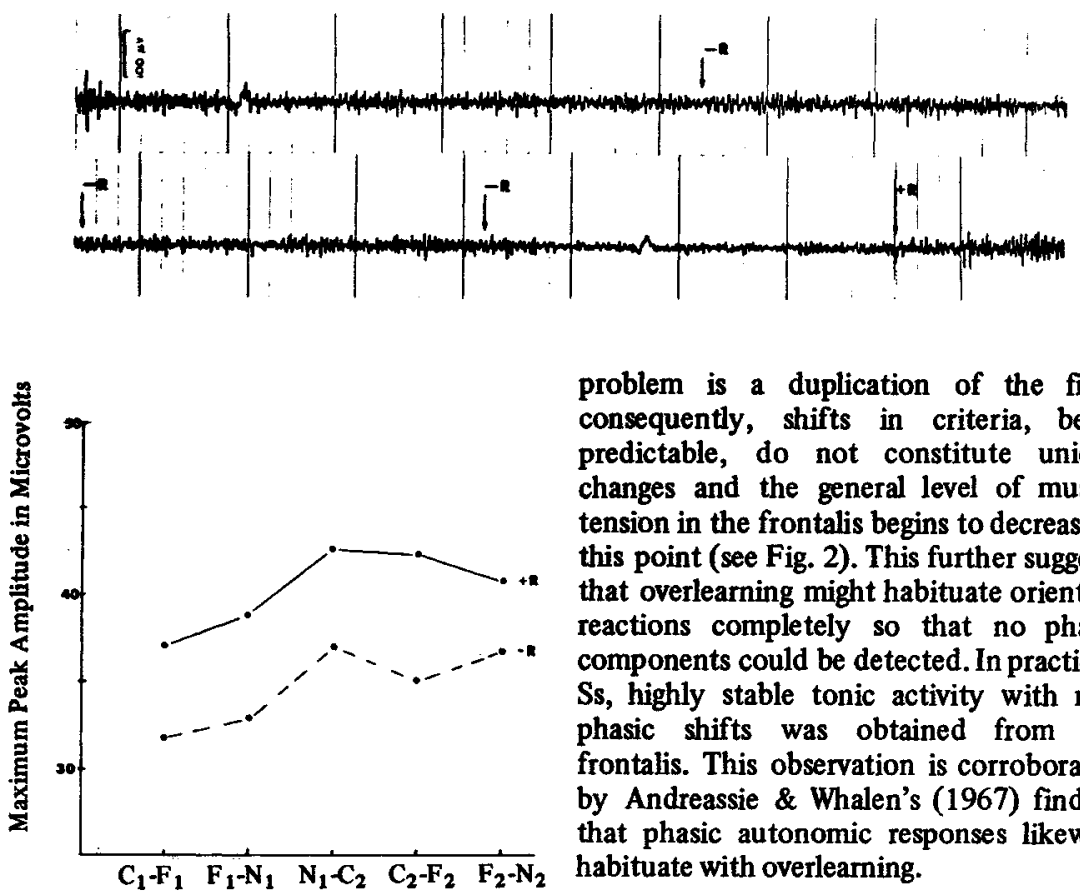

Fig. 2. Maximum peak amplitude of Frontalis EMG during last second of intertrial interval (1) following final correct $R$ and (2) first logical error at each change in criterion. Each point represents the mean amplitude of 17 subjects.

criteria were not statistically significant. Figure 2 also suggests the progressively rising gradient of muscle tension previously reported by several investigators. However, in the present study, the gradient was not monotonic as earlier results have suggested. The lack of significant EMG differences at the first change in criterion is attributed to the absence of an expectancy for change in problem at this stage, making attenuation of muscle tension following the first logical error less consistent in its appearance. Habituation probably accounts for the lack of significance at the last problem shift.

\section{DISCUSSION}

The present findings suggest a tonic neuromuscular orientation by the Ss which may be due, as Malmo (1965) believes, to the need for increasing proprioceptive input to sustain prolonged attention. However, the phasic decrease in frontalis activity when an error is made demonstrates that efferent adjustments in the tonic background are superimposed by the CNS. This adjustment would be consistent with Sokolov's (1963) conception of the orienting reflex, i.e., that phasic activity is dependent upon tonic adjustments and may take the form of either increased or decreased responses against this background. Habituation of phasic orienting reactions explains the decrease in this type of response with the final series of the task. The second part of the match-to-sample problem is a duplication of the first; consequently, shifts in criteria, being predictable, do not constitute unique changes and the general level of muscle tension in the frontalis begins to decrease at this point (see Fig. 2). This further suggests that overlearning might habituate orienting reactions completely so that no phasic components could be detected. In practiced Ss, highly stable tonic activity with rare phasic shifts was obtained from the frontalis. This observation is corroborated by Andreassie \& Whalen's (1967) finding that phasic autonomic responses likewise habituate with overlearning.

\section{REFERENCES}

ANDREASSI, J., \& WHALEN, P. Some physiological correlates of learning and overlearning. Psychophysiology, 1967, 3, 406-413.

BARTOSHUK, A. K. EMG gradients and EEG amplitude during motivated listening. Canadian

\section{JOHN M. TAUB and RALPH J. BERGER, University of California, Santa Cruz, Calif. 95060}

An investigation was undertaken of the possible effects upon performance of sleep in excess of that habitually taken. Twelve Ss worked on 15-min vigilance and calculation tasks on 2 successive days $30 \mathrm{~min}$ after either 8 or $11 \mathrm{~h}$ of nocturnal sleep. The order of sleep length and task presentation was counterbalanced among Ss. Performance on the vigilance task was significantly poorer after $11 \mathrm{~h}$ of sleep than after $8 \mathrm{~h}$ of sleep ( $p<.05)$. Performance on the calculation task was unaffected by the sleep condition. The results indicate that extended sleep can produce decrements in performance similar to those which occur with sleep deprivation.

Although numerous experiments have been conducted examining the relation of performance to sleep deprivation, none have been undertaken to study the possible behavioral effects of sleep in excess of that usually taken. The only investigation in this area was concerned with the physiological
Fig. 1. Progressive decrease in Frontalis EMG activity associated with consecutive errors, and return to previous levels following correct response.

Joumal of Psychology, 1956, 10, 156-164.

LESHNER, S. Effect of aspiration and achievement on muscular tensions. Journal of Experimental Psychology, 1961, 61, 133-137.

MacNEILAGE, P. Changes in electroencephalogram and other physiological measures during serial mental performance. Psychophysiology, 1966, 2,344-353.

MALMO, R. Physiological gradients and behavior. Psychological Bulletin, 1965, 64, 225-234.

REUDER, M. The effect of ego orientation and problem difficulty on muscle action potentials. Journal of Experimental Psychology, 1956,51, 142-148.

SOKOLOV, E. Perception and the conditioned reflex. New York: Pergamon Press, 1963.

STENNETT, $R$. The relationship of performance level to level of arousal. Joumal of Experimental Psychology, 1957, 54, 54-61.

SURWILLO, W. Psychological factors in muscleaction potentials: EMG gradients. Journal of Experimental Psychology, 1956, 52, 263-272.

\section{NOTE}

1. This investigation was supported in part by Research and Training Center Grant RT-10 from the Social and Rehabilitation Service, Department of Health, Education and Welfare, Washington, D.C.

\title{
Extended sleep and performance: The Rip Van Winkle effect ${ }^{1}$
}

patterns of extended sleep (Verdone, 1968). Although the amount of rapid-eyemovement (REM) sleep increases with time throughout a typical night of $8 \mathrm{~h}$ of sleep (Feinberg, Koresko, \& Heller, 1967; Kales, Wilson, Kales, Jacobson, Paulson, Kollar, \& Walter, 1967), Verdone found that persons sleeping beyond $7 \mathrm{~h}$ or $8 \mathrm{~h}$ had a constant percentage of sleep in this stage, with no evidence that REM sleep "overflowed" to subsequent nights.

Although the question of how much sleep we require has not been systematically investigated, studies on persons living in the Antarctic under conditions of continuous daylight showed them to average $8 \mathrm{~h}$ of sleep each night (Kleitman \& Kleitman, 1953; Lewis \& Masterson, 1957). A recent survey obtained an average duration of sleep of $7 \mathrm{~h}$ $36 \mathrm{~min}$ over ages 20 through 80 , with higher figures reported by the youngest and oldest age groups (Tune, 1968). Taking $8 \mathrm{~h}$ as a normal amount of sleep and on the basis of phenomenological subjective reports of "grogginess" by persons when occasionally sleeping longer than this amount, this study tested the hypothesis that sleep in excess of that habitually taken is deleterious and 
Table 1

Total Number of Signals Detected on Vigilance Task after 8 and $11 \mathrm{~h}$ of Sleep

\begin{tabular}{lll}
\hline & \multicolumn{2}{c}{ Condition } \\
\cline { 2 - 3 } $\mathrm{S}$ & $8 \mathrm{~h}$ & $11 \mathrm{~h}$ \\
\hline 1 & 15 & 13 \\
2 & 15 & 15 \\
3 & 15 & 14 \\
4 & 15 & 13 \\
5 & 15 & 12 \\
6 & 15 & 12 \\
7 & 15 & 14 \\
8 & 14 & 12 \\
9 & 13 & 12 \\
10 & 13 & 15 \\
11 & 11 & 11 \\
12 & 15 & 14 \\
Means & 14.3 & 13.1 \\
\hline
\end{tabular}

would be reflected by decrements in performance measures following nights of extended sleep.

\section{SUBJECTS}

Subjects were seven female and five male students of college age. They were screened with the Cornell Index and it was determined that they were free from evident medical or psychiatric disorder. Another criterion used for selection of Ss was that they usually slept approximately $8 \mathrm{~h}$ nightly.

\section{PROCEDURE}

The Ss were requested to abstain from the use of stimulating or soporific drugs and the taking of naps on days prior to the experiment. They were also asked not to drink coffee, tea, or alcohol after 6 p.m. They were told the purpose of the experiment was to investigate the psychological effects of "extra" sleep.

The experiment comprised of two consecutive nights of sleep for each $\mathrm{S}$. Ss slept $8 \mathrm{~h}$ on one night, from 1 a.m. to 9 a.m., and $11 \mathrm{~h}$ on the other night, from 10 p.m.to 9 a.m. A calculation and a vigilance task, similar to those used by Wilkinson, Edwards, \& Haines (1966), were administered as measures of performance $30 \mathrm{~min}$ after

Table 2

Accuracy Score on Vigilance Task as Errors of Commission Subtracted from Possible Number of Signals Detected (15) after 8 and $11 \mathrm{~h}$ of Sleep

\begin{tabular}{lll} 
& \multicolumn{2}{c}{ Condition } \\
\cline { 2 - 3 } $\mathrm{S}$ & $8 \mathrm{~h}$ & $11 \mathrm{~h}$ \\
\hline 1 & 15 & 13 \\
2 & 10 & 10 \\
3 & 15 & 14 \\
4 & 15 & 13 \\
5 & 13 & 12 \\
6 & 14 & 12 \\
7 & 14 & 14 \\
8 & 14 & 12 \\
9 & 13 & 12 \\
10 & 13 & 10 \\
11 & 11 & 11 \\
12 & 15 & 14 \\
Means & 13.5 & 12.3 \\
\hline
\end{tabular}

awakening, at 9:30 a.m. each morning. A fixed time of testing ruled out possible effects on performance attributable to variations in circadian rhythm. Order of task presentation and conditions of sleep were counterbalanced among Ss.

The calculation task consisted of adding columns of five two-digit numbers with Ss instructed to solve as many problems as possible in the given time period of $15 \mathrm{~min}$. The vigilance task constituted a series of doorbell buzzes occurring at $2.5-\mathrm{sec}$ intervals, which were recorded on magnetic tape. The duration of each buzz was $.4 \mathrm{sec}$ with the exception of 15 of them that lasted $.6 \mathrm{sec}$. These 15 buzzes of longer duration were interspersed at irregular intervals throughout the recordings so that they appeared random to the Ss. Ss were directed to indicate detection of these signals by marking a check on a blank score card. Duration of this task was also $15 \mathrm{~min}$.

Table 3

Scores on the Calculation Task as Number of Problems Solved Correctly in $15 \mathrm{Min}$ after 8 and $11 \mathrm{~h}$ of Sleep

\begin{tabular}{ccc}
\hline & \multicolumn{2}{c}{ Condition } \\
\cline { 2 - 3 }$S$ & $8 \mathrm{~h}$ & $11 \mathrm{~h}$ \\
\hline 1 & 52 & 53 \\
2 & 40 & 38 \\
3 & 37 & 44 \\
4 & 28 & 28 \\
5 & 23 & 35 \\
6 & 24 & 34 \\
7 & 40 & 36 \\
8 & 48 & 43 \\
9 & 46 & 43 \\
10 & 77 & 51 \\
11 & 63 & 34 \\
12 & 47 & 39 \\
Means & 42.9 & 39.8 \\
\hline
\end{tabular}

Different buzzer programs were used so that occurrence of the prolonged stimuli varied from one session to another.

The score for the calculation task was the number of problems solved correctly. For the vigilance task, two measures of performance were taken: (1) total number of signals detected, and (2) an "accuracy score," obtained by subtracting the total number of errors of commission from the total number of 15 signals.

The experiment was conducted in the quiet environments of the Ss' bedrooins. All clocks were out of view so that Ss were not aware of test duration, and $E$ left the room to avoid distracting the Ss. Two Ss were tested each day, each doing a different task simultaneously, but in separate rooms. Each test followed the other within a 2-min period.

\section{RESULTS}

Performance on the vigilance task was significantly poorer after $11 \mathrm{~h}$ of sleep than after $8 \mathrm{~h}$ of sleep for both scores: total number of signals detected (Table 1; $\mathrm{p}<.05$, Wilcoxon test) and accuracy (Table $2 ; p<.01$, Wilcoxon test).

Although the mean score on the calculation task was higher following the 8-h sleep condition than after the 11-h condition (Table 3), this difference was not statistically significant $(p>.05$, Wilcoxon test).

\section{DISCUSSION}

The main finding of this experiment, that sleep in excess of the normal quota of $8 \mathrm{~h}$ impairs vigilance, may appear somewhat surprising when considered in relation to the commonly held view that sleep serves a purely recuperatory function. However, after completing this study we learned that Globus (in press) had recently independently confirmed in a systematic study our original notion that Ss tend to feel "groggy" when sleeping in excess of their usual amounts.

The vigilance task appeared to be a sensitive measure of performance in this study and the earlier one, from which it was derived, on the effects of varying amounts of sleep deprivation (Wilkinson et al, 1966). However, the results of that experiment raise questions concerning the extent to which calculation tasks are sensitive enough to reveal variations in performance as a function of differing levels of alertness. In the study by Wilkinson et al, less than $5 \mathrm{~h}$ of sleep on a single night led to impaired vigilance, but calculation scores only began to show a decrement when Ss slept $3 \mathrm{~h}$ or less.

The results of this experiment certainly suggest that the effects of extending sleep beyond $8 \mathrm{~h}$ or one's normal quota may be deleterious. In further studies it is planned to test whether performance shows an inverted U-function in relation to length of sleep, with the apex occurring at $8 \mathrm{~h}$ or the amount of sleep a person habitually takes.

\section{REFERENCES}

GLOBUS, G. G. Sleep duration and feeling state. In E. Hartmann (Ed.), International psychiatric clinics. Boston: Little-Brown, in press.

KLEITMAN, N., \& KLEITMAN, H. The sleep-wakefulness pattern in the Arctic. Science Monthly, 1953, 76, 349-356.

LEWIS, H. E., \& MASTERSON, H. P. Sleep and wakefulness in the Arctic. Lancet, 1957, 1 , 1262-1266.

TUNE, G. S. Sleep and wakefulness in normal human adults. British Medical Journal, 1968, 2, 269-271.

VERDONE, P. Sleep satiation: Extended sleep in normal subjects. Electroencephalography \& Clinical Neurophysiology, 1968, 24, 417-423.

WILKINSON, R. T., EDWARDS, R. S., \& HAINES, E. Performance following a night of reduced sleep. Psychonomic Science, 1966, 5 , 471-472.

\section{NOTE}

1. Address requests for reprints to Ralph $J$. Berger, $\mathrm{PhD}$, Crown College, University of California, Santa Cruz, California 95060. 